\title{
Education Language Policy in Mozambique: A Critical View
}

\author{
Mira de Jesus Varela Canhanga, BEd \\ Pedagogic University, Gaza, Mozambique \\ Dr. Martin Banda, PhD
}

\author{
Department of Educational Psychology and Sociology \\ Kwame Nkrumah University, P.O. Box 80404, Kabwe-Zambia
}

\begin{abstract}
The article evaluates the current language policy adopted by the Mozambican government as stated in the Constitution of the Republic of Mozambique and in the article 4 of decree 6/92 on the National Education System. We are of the opinion that coming up with the most suitable language policy is a key element in national building and particularly in the individual citizens' welfare. Thus, we argue that the analysis of the current language policy is of paramount importance. The study shades light to the government officials, the Ministry of Education officials, teachers, students and all education stakeholders at large in the implication of the current Education language policy for Mozambique.
\end{abstract}

Keywords: The concept language policy; language policy; Bilingual Education; Model and Programmes; the Relevance of a Bilingual Education; the Model of Bilingual Education; An Ideal Education Language Policy.

\section{BACKGROUND}

Due to the nomadic life, and later on with the advancement in the field of navigation as well as trade, people's geographical and social mobility increased as compared to the motion in the early civilizations. These led to not only a wider interaction between different languages but also to the emergence of new ones. According to Crystal (2003) there are about 6, 000 languages in the world. Chimbutane (2009) posits that in Mozambique alone there are over 20 Bantu languages in addition to Portuguese, English and some South Asian languages.

The quest for a consensus language to use in different social encounters has become a matter of concern to many politicians, educationists, linguists and the society in general. Governments worldwide are increasingly showing their interest in coming up with a sustainable policy to regulate the use of languages in schools as well as in the public service institutions.

However, coming to a consensus on the choice of an official language and the language to be used in education and public service institutions is never an easy feat. Political, cultural and economic interest may diverge in this endeavor. Consequently, governments may come up with a language policy which is either not compactable with the needs of the country or which is not comprehensible enough to those directly involved in the implementation of the policy.

As a matter of evidence, the Education Language Policy for Mozambique is not all that clear for educationists and most particularly primary school teacher educators. This may lead to the distortion of the objective and the principles set in the policy and consequently poor school performance.

\section{Methodology}

The study is rather qualitative since we intend to interpret complex aspect of the phenomenon and people's attitudes towards the implementation of Bilingual Education. We interviewed some teachers involved in bilingual education in Chimondzo Primary School, one of the sixteen schools piloting the program in the country and tested students' performance in the same school in both groups, the controlled group and the experimental group to compare their level of performance.

\section{Language Policy}

The concept language policy means the official regulation of the type of language to use in a given institution, nation or organizations with of a view to guide speakers in their social proceedings. This 
may be done at the level of institutions or at the nation level. For the purpose of this paper we are going to limit our discussion to the education language policy.

According to Henriksen (2010:90) Language Policy is a set of decisions regarding the language to be taught, the intervenient, the time span, the methodological approaches, the official status of a language ,the context in which it has to be taught and its implementation strategies.

However the definition above is not quite comprehensive and appropriate for our discussion, it only covers the education language policy domain. A part from this domain one can talk about a national, a regional or even an institutional language policy. As a matter of evidence, organizations such as the SADC, UN and Commonwealth have their language policies that regulate their formal proceedings, it is usually written but in less formal organizations it is just assumed.

A language police may also be considered as a conscious and official action that seeks to intervene in languages at national, regional, minority or foreign levels with respect to their forms (the writing system), social functions (choice of language as official language) or their place in education based on economic, socio-cultural and political motivations. ibid 90

The author gives a more comprehensible and wide ranged definition of the concept language policy and she puts forward the factors that underlie a good language policy. This definition will help us throughout our discussion to evaluate the suitability of the education language policy set by the Mozambican government. In other words, we position to see if the current Mozambican Education language policy meets the needs of the citizens at the economic, socio-cultural, educational and political domains.

\section{Mozambican Language Policy}

Mozambique as many other countries and formal institutions adopted a language policy to regulate the use of languages in public services as well as in social proceedings. This is outlined in the national Constitution of 1990 and in the revised version of 2004 as follows.

(1) "In the Republic of Mozambique, the Portuguese language shall be the official language;"

(2) "The state shall value the national languages and promote their development and their growing usage as vernacular languages and in the education of citizens." (Article 5 of the 1990 Constitution of the Republic)

Although there is a language policy outlined in this constitution there is not much said about how the state will value and promote the development of the national language and they are no specific budgets for this project. Besides, recurrent practices in the dominating use of Portuguese over the Mozambican national languages suggested that statement 2 of Article 5 does not go any further than the level of lip service.

For instance in schools, teachers consistently keep interjecting the learner from using their national languages. The media of instruction is still Portuguese dominating; the political leaders with some exceptions continue to use Portuguese exclusively in their functions even in contexts where a national language could be used. Some public servants stick to the use of Portuguese to people seeking their services even if they know that using Portuguese would be far more productive. The amount of national languages in the Mozambican media is still far from the desirable.

This attitude that could be interpreted as people's negative attitude towards the use of national languages or rather lead to a bias against the national languages particularly in public service institutions was bred for ages due to the language policy adopted by the Portuguese colonizers during their rule in Mozambique and then by FRELIMO party in the aftermath of the Independence. As Ngoenha (2000) puts it, the Portuguese government entrusted the education system to the Missionaries and one of the objectives was to make the natives use Portuguese and this implied the imposition of the Portuguese language.

The education language policies adopted reflected the general colonial philosophies adopted by the colonial power. For instance Portugal and France were consonant with their assimilationist philosophy which advocated for the exclusive use of Portuguese in education institutions and public services (Chimbutane 2009). Even after the Independence, FRELIMO adopted a policy of national language exclusion not for civilization purposes as intended in the colonial era but for the purpose of fostering national unity. 
As we have previously mentioned, the influence of this two language policies have shaped the minds of a significant number of Mozambicans who up to today have negative attitudes towards the use of national languages in the public institutions including in education.

With the 2004 Constitution revision, the element of the promotion of people's identified through the use of the national languages was highlighted. According to Chapter I, Article 9, "the nation values the national languages as cultural and educational heritage and promotes their development and increased usage as languages that portray people's identity."

As a way of backing the implementation of the language policy outlined in Article 9 of the Constitution mentioned previously, the Ministry of Education issued the article 4 of decree 6/92 on the use of African languages in education in the following lines. 'Under the framework defined within the current decree, the National Education System must value and develop the national languages, promoting their gradual introduction in the education of the citizens' (RM, 1992, p.104). ibid 93

All the same, the language education policy in place in Mozambique is not yet clear or rather is not well interpreted by the users and the place of the national languages in schools is still obscure. It is for this reason that Chimbutane (2009) brings in the term "de facto education policy" when he argues that the de facto education policy now in place in Mozambique can be regarded as multilingual: in addition to Portuguese, 16 African languages now being used as initial media of instruction. In a nutshell, there is a language policy set and outlined in the constitution of the Republic of Mozambique which is not being used, and there is another language policy what the author terms de facto language policy being used in the country which is not ascribed in the constitution.

\section{Bilingual Education}

In many parts of the world there are education systems that adopt more than one language as a medium of instruction to cater for the needs of the learners who may not be fluent enough to attend the courses offered in a given language. Most often than not, these are learners coming from minority linguistic groups or immigrants attending classes together with learners with a good back ground of the dominating language.

Henriksen (2010) defines bilingual education as the use of two or more languages as medium of instruction in classrooms not necessarily in a balanced way, which means one language can be used more than the other depending on the needs of the learners and the objectives of the lesson and the philosophy of education in place.

We are told that bilingual education existed since the early periods of formal education. According to Edwards (2005) the history of bilingual education backs to the time of the Greek civilizations and it has been implemented all through in different parts of the world. Formal instruction in schools in both languages was largely modeled on the Greek curriculum during the time of the Roman Empire, English and Chinese in Singapore, English and Maltese in Malta and Swahili and English in Tanzania just to mention a few.

Although this practice is quite old in the history of formal education, due to economic constraints, social pressure, political ideologies and education philosophies it has never been easy to come up with clear policies to promote bilingual education in many countries, Mozambique included. With the rapid changing world and the uncertainty of the future, educationist or rather philosophers of education like Ngoenha (2000) and Castiano (2005) have started questioning whether schools should prepare children for a competitive society with a view to facing the current competitive world and the free market or to prepare children for what Castiano in the book A Longa Marcha Duma Educação Para Todos em Moçambique ${ }^{l}$ (2005) calls "Mozambicanity."

Worldwide, with the advent of globalization and regional integration governments are faced with this dichotomy with some adopting education programmes geared to the globalization, regional integration and free market and others sticking to their national identity.

In Africa due to the lack of resources, dependence to the western powers and their political interests the exercise is much more difficulty, perhaps less more difficult now than at the early years of Independence.

\footnotetext{
${ }^{1}$ The Long March of An Education For All in Mozambique
} 
"African nations have been confronted with a problem of reconciling the quest for efficiency and the quest for authenticity. In terms of language choice, claims for authenticity (sociocultural integration) calls for the adoption of an indigenous language, while claims for efficiency, (political integration) calls for any language that can perform these functions. (Fishman, 1968) quoted in Kaplan and Baldauf (2004). In Mozambique the choice of the language policy or rather the language policy adopted at the advent of the Independence was motivated by the claim of efficiency which entailed the choice of Portuguese as the official language and the exclusive use of Portuguese as the language of instruction in formal learning institutions.

\section{Models and Programmes of Bilingual Education}

The concepts modals of bilingual education and programmes of bilingual education are most often than not used interchangeably. However, some sociolinguist among them Drawing on Trueba (1979), Hornberger (1991) (qtd. in Chimbutane 2009:28) posit that there is a difference between bilingual education model and programme types. They suggest that models are temples for programmes.

For the purpose of this paper we are looking at the two concepts rather interchangeably. In other words, we will make no significant distinction between the two concepts.

Henriksen (2010) suggests that there are basically two main models of bilingual education; the maintenance model and the transitional model. She then posits that we can consider a third model which is the enrichment bilingual education. In her opinion, these models can be divided into the strong form of bilingual education which includes the immersion, maintenance or heritage language model, two-way or dual language and mainstream bilingual education. The weak form of bilingual education comprises the transitional bilingualism, the submersion or the structured immersion, the segregationist and the separatist models.

Chimbutane (2009) argues that there are three models of bilingual education (transitional, maintenance and enrichment) and two bilingual education programme types (two-way or dual language programme and immersion).

According to Edwards (2005) there are five types of bilingual education models (immersion, submersion, addictive bilingual education, subtractive bilingual education, primary and secondary bilingual education.

We can suggest that each of the models and programme types of bilingual education discussed by the three sociolinguists above has its procedures and objectives as illustrated in the table below. We noticed that while Henriksen (2010) prefers to use the term minority-group and majority group language to refer to languages used by the dominated community and languages used by the dominating communities, Chimbutane (2009) uses the concepts lower-status and higher-status languages.

Table1. Bilingual Education Main Models and Programme types Chart

\begin{tabular}{|c|c|c|}
\hline $\begin{array}{c}\text { Model and } \\
\text { Programme types }\end{array}$ & Description & $\begin{array}{l}\text { Objectives } \\
\text { (Aims to...) }\end{array}$ \\
\hline $\begin{array}{l}\text { Maintenance/Heritage } \\
\text { Language Model }\end{array}$ & $\begin{array}{l}\text { Pupils from low-status language are } \\
\text { taught in their first language and } \\
\text { dominant, second language with } \\
\text { emphasis on the first language }\end{array}$ & $\begin{array}{l}\text { Strengthen lower-status pupils' culture } \\
\text { identity and affirm the right of } \\
\text { ethnolinguistic groups. Foster } \\
\text { bilingualism and biliteracy in L2. } \\
\text { Fosters language shift and cultural } \\
\text { assimilation }\end{array}$ \\
\hline Transitional Model & $\begin{array}{l}\text { Pupils of lower-status language are } \\
\text { initially taught in their L1 and then } \\
\text { through a L2 }\end{array}$ & $\begin{array}{l}\text { Foster proficiency and academic } \\
\text { achievement in L } 2 . \text { Replace the home or } \\
\text { minority language entirely by the } \\
\text { majority language. }\end{array}$ \\
\hline Enrichment Model & $\begin{array}{l}\text { A L2 does not replace L1 but it is added } \\
\text { to enable the user to function } \\
\text { adequately in the second language }\end{array}$ & $\begin{array}{l}\text { Develop and extend a lower-status } \\
\text { language, cultural pluralism and social } \\
\text { autonomy }\end{array}$ \\
\hline $\begin{array}{l}\text { Immersion } \\
\text { Programme }\end{array}$ & $\begin{array}{l}\text { Pupils from a higher-status language } \\
\text { learn a lower-status language in } \\
\text { addition to their language }\end{array}$ & $\begin{array}{l}\text { To capitalize on young children's } \\
\text { language-learning abilities, relative } \\
\text { unselfconsciousness and attitudinal } \\
\text { openness.Foster bilingualism and } \\
\text { biculturalism }\end{array}$ \\
\hline
\end{tabular}




\begin{tabular}{|l|l|l|}
\hline \hline Two-Way or Dual & $\begin{array}{l}\text { Pupils of a lower-status language learn a } \\
\text { higher-status language and pupils of a } \\
\text { higher-status language learn a lower- } \\
\text { status but both languages are used as } \\
\text { medium of instruction. }\end{array}$ & Foster bilingualism and biliteracy \\
\hline Submersion Model & $\begin{array}{l}\text { Minority-groups children learn through } \\
\text { majority group children's language }\end{array}$ & Foster linguistic assimilation \\
\hline
\end{tabular}

Source: (Chimbutane. F (2009), Edwards. J (2005) and Henriksen. S (2010)

\section{Relevance of Bilingual Education Programmes in Mozambique}

The $21^{\text {st }}$ century world is marked with globalization, regional integration, free market and people's geographical mobility as a result of technological advancements and the improvement of means of transport, communication and people's life style.

Besides, the communication facilities have greatly improved so much that regardless of where people are found they can communicate with others all over the world. Consequently, there is more interaction between users of different language than ever. Crystal (2010) suggests that around 90\% of Africans can speak more than one language; their mother tongue, other local languages and a good number of them the national official language.

In Mozambique, with the exception of Maputo city and some urban location, people are from their childhood exposed to more than one language, their mother tongue and Portuguese.

In such a linguistic diverse society and high rates of bilingualism it is nearly undeniable that any system of education should take these differences into account. Therefore the feasibility of the old held one-language education ought to be questioned.

According to Mozambique's National Institute for Statistics only 39.6\% of Mozambicans can speak Portuguese. Strictly advocating for the exclusive use of Portuguese as the medium of instruction would mean breaking the linguistic rights of $60.4 \%$ of Mozambicans.

A part from this, scientific research has consistently shown that children learn better when taught in the language they have greater proficiency. The use of the child's most fluent language which is in Africa most often than not their mother tongue fosters children self-esteem and stimulates their cognitive development.

Artigal (1995:179) (qtd. in Henriksen (2010:85) posits that "proficiency in the family language is a sine qua non prerequisite for any child's linguistic, cognitive and academic development." Besides this, the use of one's mother tongue in education particularly in the first years of schooling would foster the development of children self-esteem, awareness of their identity and would make the learning more relevant to their lives. The exclusive use of a foreign language in education may breed a sense of alienation and frustration for learners whose command is still far from the desirable.

Anzaldua (2007) arguments that "I am my language. Until I can take pride in my language, I cannot take pride in myself." This is to say that language deprivation would lead to a hindrance of the users' self-esteem and identity.

Children ought to be taught to be proud of their language by using it in education context with a view to developing their sense of pride for who they are and boosting their self-esteem which is very important in the process of learning.

Coming back to Ngoena (2000) question, "to what society should schools prepare the children? To a globalised competitive society or to a more conservative and traditional society marked by strong sense of identity?" and then taking into account the quest of efficiency and authenticity raised by Fishman (1968) (qtd. in Kaplan and Baldauf 2004), it may not be as easy as one may think it is to set an appropriate language policy, particularly because the world is changing so rapidly and it is quite difficult to predict what the future will bring to us. In our opinion there is a need of striking a balance between the two.

For Garcia (2009) bilingual education is a the only way to go about education in the $21^{\text {st }}$ century, since people from the outset of their existence are introduced to a complex network of multilingual and multicultural communication. This network is reduced by the education policies, beliefs, needs and aspirations at the global and local level. We are faced with a bilingual society that the needs of this society ought to be met in education. 
It is rather clear that bilingual education fosters learning, the building of self-esteem, awareness of self identity and increased learners' level of motivation. The intention of this paper is not to question the relevance of bilingual education in Mozambique. While we agree with the implementation of the bilingual education language policy in the Mozambican, we question the model chosen and the implementation strategies used.

\section{Bilingual Education Policy in MozambiQue}

During the colonial era with the exception of some schools held by the protestant churches among them the Sweden Mission, education was exclusively provided in Portuguese (Ngoenha 2000). With the proclamation of the Independence in 1975 the government adopted the one-language and onenation ideology keeping Portuguese as the exclusive medium of instruction as we have discussed previously.

In 1983 a draft paper from the Secretary of State suggested the establishment of a Mozambican language policy that should aim at optimal bilingualism. (Kaplan and Baldauf 2004)

This sparked discussions around the possibility of an introduction of a bilingual education in Mozambique. Lack of resources and the political instability lived in the country by then might have delayed the implementation of this project.

It was only in 1993 that, Mozambique introduced, for the first time ever, a Pilot Bilingual Education Project in Gaza and Tete, putting an end to the exclusive use of Portuguese as the only medium of instruction in the country (Henriksen 2010)

Since then efforts were made to expand bilingual education still at the piloting phase throughout the country. It is for this reason that in 2003 the number of provinces piloting this system of education increased. Today there are 16 schools throughout the country administrating a bilingual education.

According to the reports published so far on the outcomes of the bilingual education the experience has provided successful. Teachers and education stakeholders involved in the bilingual education recurrently report that learners in bilingual education show higher levels of motivation, class participation and academic performance when compared to their counterparts undergoing the monolingual education. We could then say that the objectives of the bilingual education as outlined below are being met.

The above information seems to contradict the findings we came up with in a study we carried out in a school in Gaza province where the results of a test showed that students who go through the bilingual education when they go to grade 7 face problems in writing. As a matter of evidence, they use the letter $\boldsymbol{k}$ instead of $\boldsymbol{c}$ in the writing of the word Carla, they have problems in using the letter $\boldsymbol{c}$ and other accents. In other subjects students under the bilingual education system seemed to have better results though the differences were not all that significant.

The main aims of the Bilingual Education Program were to contribute to the improvement of the quality of basic education in Mozambique. It is supported by international research and practice pointing to the academic and cognitive advantages of the use of the mother tongue in initial schooling (UNESCO 1953; Benson 1997; Trudell 2008)." Henriksen 2010

Although we have this positive reports with regards to the implementation of the bilingual education, parents and other stakeholders, teachers included are rather sceptical about the outcomes of the bilingual education.

When one talks to teachers directly involved in bilingual education may have too perceptions; (1) they have not fully understood the philosophy behind the bilingual education or (2) there is a lot about the implementation of bilingual education that is not published in the reports.

We heard, though from sources yet to prove, that parents who have their children attending bilingual education have been pressing the school administration to have them in the monolingual education, at least in one school in Niassa province and two schools in Gaza, simply because they do not believe in this education system and find that their children are being left behind. These things are hardly ever reported. Should this be true, then we might be analysing an instrumentalized system of education.

Henriksen (2010) suggested that one of the major limitations of her study was that she only analyzed the attitude of children in schools in the southern part of the country. We feel the same limitation 
because the two main sources we had access to in our discussion were studies made in the southern part of the country. As the author puts it, due to the linguistic diversity which is more marked in the northern part of the country, the attitude people have to bilingual education may be different from the one in the southern part of Mozambique.

Besides, due to the massive presence of the Portuguese in the central part of Mozambique particularly in Sofala and Zambezia which is seen by the numbers of religious infrastructures built and the presence of different companies, the process of assimilation was taken positively there. We would like to see if the same attitudes to bilingual education is shared by these peoples.

\section{The Modal of Bilingual Education Adopted in MozambiQue}

Out of the models and programmes of bilingual education discussed by (Chimbutane 2009; Edwards, 2005 and Henriksen, 2010) the Ministry of Education opted the choice of the transitional bilingualism model with the aim of improving learners' competence of Portuguese, which will then lead to better academic performance.

In the Mozambican context an early-exit transitional bilingual programme has been designed. Given its structure and declared aim, it is officially defined as 'a transitional programme with maintenance characteristics' (INDE/MEC, 2003:31)." Chimbutane 2009

According to this model and according to the INDE/MEC (2003:45) a local language is used alongside with Portuguese as a medium of instruction from Grades 1 to 3 and as a subject in the curriculum, all through the primary school. However, it can be used in the rest of the primary school when introducing a new topic, or topics not familiar to the learners.

It is also clearly stated in INDE/MEC (2003) that as the learners' progress from Grade 1 to Grade 7 the amount of the national language used as a medium of instruction is reduced from $90 \%$ in Grade 1 , to $75 \%, 60 \%, 40 \%, 25 \%, 20 \%$ and $20 \%$ in Grade 7 respectively. As the amount of the national language decreases as the learners progress from Grade1 to 7, the amount of Portuguese used as a medium of instruction increases.

\section{ANALYSis OF THE MODEL}

As we discussed under bilingual education models and programmes the main goals of the transitional model is to foster proficiency and academic achievement in second language, to replace the home or minority language entirely by the majority language. That is why after the transitional phase in Grade 3 the programme ends in Grade 7, there is no continuity in secondary and tertiary education.

According to our point of view, there are three problems with this model of bilingual education adopted by the Mozambican Ministry of Education that ought to be addressed.

First, according to the language policy outlined in the Mozambican constitution particularly in Chapter I, Article 9 as previously mentioned "the state values the national languages as cultural and educational heritage and promotes their development and increased usage as languages that portray people's identity."

The choice of the transitional model of bilingual education, a model associated with majority-group language assimilation or a dominant language assimilation will not foster the development neither will it foster the increased usage of languages that portray people's identity. There is a common tendency to associate transitional programmes with cultural assimilation and consequent loss of pupils' first languages (Chimbutane 2009).

We would suggest the adoption of the enrichment model, a model that aims to develop and extend a lower-status language, cultural pluralism and social autonomy. We are of the opinion that this model would be more compactable with the Mozambican language policy as outlined in the Republic Constitution.

Secondly, since one of the objectives of bilingual education is to foster lower-group language identity we suggest that the national languages be taught all through the Mozambican system of education. This would enable teachers to transmit the richness in the national languages found in proverbs, riddles, myths and in the African oral literature. In other words, stopping the teaching of the national languages in Grade 7, and this is the stage when children have not yet developed full awareness of their identity would be counterproductive. Although the initial years of one's education are crucial in the shaping of their personality lack of continuity may hinder that intended effects. 
Thirdly, modern language teaching methods particularly the natural approach (Stephen Krashen), Silent Way (Gattegno), the audio-lingual method (Charles Fries), TPR (James Asher), the direct method and the communicative approach discourage the use of translation in the teaching of languages, no native language is allow in some modern methods and in others a very minimum amount of native language can be used in the teaching of the target language (Freeman 2000).

According to the proponents of these methods the exclusive use of the target language will provide learners with the roughly tuned input need to foster communication. However, the bilingual education adopted posits that $\mathbf{L} \mathbf{2}$ should be taught in $\mathbf{L 1}$. We would suggest that the national languages be used as medium of communication in all the subjects other than Portuguese in the initial grades and Portuguese be taught exclusively in Portuguese with tolerance to the use of national languages when need be. This would require a lot of preparation and creativity among the teachers of Portuguese but in the long run the experience could prove a success.

\section{An Ideal Education language Policy for the 21st Century Mozambican SOCIETY}

An ideal education language policy for Mozambique in $21^{\text {st }}$ century would be the adoption of the enrichment model of bilingual education not the transitional model in place in the 16 bilingual education piloting schools. In the model we suggest, the national languages will be taught as a compulsory subject both at the primary and secondary education levels in Mozambique with a view to providing learners with the opportunity to learn and acquire the knowledge and cultural values hidden in these languages at a stage when they have already matured their cognitive skills.

Castiano et al (2005) postulate that unity is intrinsically associated with the value of diversity ${ }^{2}$. Should this be considered true, then we believe that the compulsory teaching of the national languages will not hamper the national unity as argued before by many critics of bilingual education on the contrary it will foster national unity.

Considering the linguistic diversity throughout the country but particularly in Maputo city, highly populated urban cities in Mozambique and in the northern part of the country we suggest that the teaching of national languages should not be done in the usual classes but each schools should determine a day and time when learners are grouped according to their mother tongue and a teacher or a community member is assigned to assist the group.

In case the group is too small and there is no one in the community with fluency in their language, the school administration should negotiate with the parents to find one of the national languages offered at the school for their children to learn or to have one of the parents of the group administering lessons in the language.

Schools could set the last two periods of the week such as Fridays for national language teaching. Then classes would stop in the fourth period and learners would join their specific group for the national language learning.

At the beginning of each year, schools would be asked by the district pedagogic department officer to submit their national language programme and strategic plans for the minority groups and at the end of each term each teacher assisting a group in national language teaching would produce a report and submit to the district officials.

A team of supervisors, not inspectors from the district education department would be assigned the responsibility of supervising the teaching of national languages and provide support to both teachers and learners in the process.

\section{Conclusion}

The model of bilingual education policy adopted by the Ministry of education in the 2003 curriculum reforms is not compactable with the language policy outlined in the revised version of the constitution of the Mozambican republic.

In order to reconcile the allusion, we suggest that a new model be adopted and supported by supervising teams assigned by education district officers. In other word, the transitional model of

\footnotetext{
${ }^{2}$ A unidade esta intrinsecamente ligada ao valor da diversidade (Castiano et al 2005: 269)
} 
bilingual education adopted for the Mozambican education is oriented to the assimilation of the majority-group language and culture. Thus, this model contradicts the principle of language policy outlined in statement 2 of article 9 of the Mozambican constitution.

We therefore propose that this model be replaced by the enrichment model of bilingual education to which we are of the opinion that this will enhance academic performance of learners and at the same time will boost their self-esteem and cultural identity.

\section{RECOMMENDATIONS}

After this discussion under the topic education language policy in the Mozambican system of education it is recommended that:

$\checkmark$ A study should be carried about attitudes of learners and education stakeholders about the national languages in the northern part of Mozambique to compare with the results got in the two studies made;

$\checkmark$ A constant supervision of the bilingual education program should be made by experts on the area;

$\checkmark$ Support should be given to teachers and learners involved in the projects;

$\checkmark$ Parents ought to be heard about their feeling with regards to the introduction of bilingual education;

$\checkmark$ Teacher educators ought to be informed and prepared to pass on the experience to the would be teachers;

$\checkmark$ Further analysis of the current model of bilingual education should be done in order to improve its implementation or change the model and

$\checkmark$ Parents should be explained about the importance of the bilingual education.

\section{REFERENCES}

[1] CRYstal, D. The Cmbridge Encyclopedia of Language. Cambridge University Press. 2010

[2] CHIMBUtANE, F. The Purpose and Value of Bilingual Education: A Critical, Linguistic Ethnographic Study of Two Rural Primary Schools in Mozambique. University of Birmingham, A Thises for $\mathrm{PhD}, 2009$.

[3] HENRIKSEN, S. Language Attitudes in a Primary School: A Bottom-Up Approach to Language Education Policy in Mozambique. Roskild University Department of Culture and Identity: A Thises for $\mathrm{PhD}, 2010$

[4] NGOENHA, S. Estatuto e Axiologia da Educacao. Maputo. Livraria Universitária. 2000

[5] ChIMBUtAnE, F. The Purpose and Value of Bilingual Education: A Critical, Linguistic Ethnographic Study of Two Rural Primary Schools in Mozambique. University of Birmingham, A Thises for $\mathrm{PhD}, 2009$.

[6] ChIMButAnE, F. The Purpose and Value of Bilingual Education: A Critical, Linguistic Ethnographic Study of Two Rural Primary Schools in Mozambique. University of Birmingham, A Thises for $\mathrm{PhD}, 2009$.

[7] HENRIKSEN, S. Language Attitudes in a Primary School: A Bottom-Up Approach to Language Education Policy in Mozambique. Roskild University Department of Culture and Identity: A Thises for $\mathrm{PhD}, 2010$

[8] EDWARDS, J. Multilingualism. New York. Penguin Books Ltd. 2005

[9] NGOENHA, S. Estatuto e Axiologia da Educacao. Maputo. Livraria Universitária. 2000

[10] Castiano, J et al. A Longa Marcha Duma Educação Para Todos Em Moçambique. Maputo. Imprensa Universitária. 2005

[11] KAPLAN, R and BALDAUF, R. Language Planning and Policy in Africa Vol.1 Botswana, Malawi, Mozambique and South Africa. Great Britain. Cromwell Press Ltd. 2004

[12] CHIMbutAne, F. The Purpose and Value of Bilingual Education: A Critical, Linguistic Ethnographic Study of Two Rural Primary Schools in Mozambique. University of Birmingham, A Thises for $\mathrm{PhD}, 2009$. 
[13] HENRIKSEN, S. Language Attitudes in a Primary School: A Bottom-Up Approach to Language Education Policy in Mozambique. Roskild University

[14] CHIMBUTANE, F. The Purpose and Value of Bilingual Education: A Critical, Linguistic Ethnographic Study of Two Rural Primary Schools in Mozambique. University of Birmingham, A Thises for $\mathrm{PhD}, 2009$.

[15] EDWARDS, J. Multilingualism. New York. Penguin Books Ltd. 2005

[16] CHIMBUTANE, F. The Purpose and Value of Bilingual Education: A Critical, Linguistic Ethnographic Study of Two Rural Primary Schools in Mozambique. University of Birmingham, A Thises for $\mathrm{PhD}, 2009$.

[17] HENRIKSEN, S. Language Attitudes in a Primary School: A Bottom-Up Approach to Language Education Policy in Mozambique. Roskild University

[18] CHIMBUTANE, F. The Purpose and Value of Bilingual Education: A Critical, Linguistic Ethnographic Study of Two Rural Primary Schools in Mozambique. University of Birmingham, a Thises for $\mathrm{PhD}, 2009$.

[19] CRYstal, D. The Cmbridge Encyclopedia of Language. Cambridge University Press. 2010

[20] ANZALDUA. G. Borderlands/ La Frontera: The New Mestiza. Aunt Lute Books. www. Auntlute. com. 2007

[21] INDE/MEC. Plano Curricular do Ensino Secundario Geral. Maputo. INDE/MEC 2003

[22] FREEMAN, Diane. Teaching and Principles in Language Teaching. New York. Oxford University Press. 2004

[23] Castiano, J et al. A Longa Marcha Duma Educação Para Todos Em Moçambique. Maputo. Imprensa Universitária. 2005

\section{AUTHORS' BIOGRAPHY}

Mira de Jesus Varela Canhanga, is a lecturer in Applied Linguistics and the English Language Teaching Course Director at the Department of Sciences of Language, Communication and Arts at the Pedagogic University of Mozambique at Gaza Campus. He holds a BEd (Catholic University of Eastern Africa-Kenya) and he is a current a Masters' student in Education (English Language Teaching) at the Pedagogic University of Mozambique.

$\mathrm{He}$ is interested in researching on Language Policies, The Use of Authentic Material in Teaching, Managing Available Teaching Materials in under resourced Schools and Innovative Teaching Approaches feasible for the teaching context. He also has a special interest in Religious Maters, particularly in Bible interpretation.

Martin Banda, is a Lecturer for Sociology and is currently the Head of Department of Educational Psychology and Sociology in the School of Education at Kwame Nkrumah University-Zambia. He holds PhD and MA:Ed in Sociology of Education from the University of Zambia, a Bachelor of Arts in Education (Catholic University of Eastern Africa-Nairobi). His main research interests are in Sociology of Education, Education and Society, Endogenous Knowledge Systems, Education Change and Pedagogical Transformation, HIV/AIDS, Sex Education and Curriculum Studies. 